\title{
Cod liver oil intake and incidence of asthma in Norwegian adults-the HUNT study
}

\author{
Xiao-Mei Mai, ${ }^{1}$ Arnulf Langhammer, ${ }^{1}$ Yue Chen, ${ }^{2}$ Carlos A Camargo $\mathrm{Jr}^{3}$
}

\begin{abstract}
${ }^{1}$ Department of Public Health and General Practice, Norwegian University of Science and Technology, Trondheim, Norway ${ }^{2}$ Department of Epidemiology and Community Medicine, University of Ottawa, Ottawa, Ontario, Canada ${ }^{3}$ Department of Emergency Medicine, Massachusetts General Hospital, Harvard Medical School, Boston, Massachusetts, USA
\end{abstract}

\section{Correspondence to} Dr Xiao-Mei Mai, Department of Public Health and General Practice, Faculty of Medicine, Norwegian University of Science and Technology, Trondheim 7491, Norway; xiao-mei.mai@ntnu.no

Received 18 April 2012 Revised 14 August 2012 Accepted 15 August 2012 Published Online First 12 September 2012

\footnotetext{
To cite: Mai X-M, Langhammer $A$, Chen $Y$, et al. Thorax 2013, 68, 25-30.
}

\section{ABSTRACT \\ Background Cod liver oil is an important source of vitamin $D$, but also contains other fat-soluble components such as vitamin A. Before 1999, the cod liver oil formula in Norway contained a high concentration of vitamin A (1000 $\mu \mathrm{g}$ per $5 \mathrm{ml})$. High vitamin A status is associated with increased risks of several chronic diseases.}

Objective To investigate the association between cod liver oil intake and asthma development.

Methods In the Nord-Trøndelag Health Study, a total of 25616 Norwegian adults aged 19-55 years were followed up from 1995-1997 to 2006-2008. Current analysis based on 17528 subjects who were free of asthma and had complete information on cod liver oil intake at baseline. Cod liver oil intake was defined as daily intake $\geq 1$ month during the year prior to baseline. Incident asthma was reported as new-onset asthma during the 11-year follow-up.

Results Of the 17528 subjects, 18\% ( $n=3076)$ consumed cod liver oil daily for $\geq 1$ month over the past year. Cod liver oil intake was significantly associated with incident asthma with an OR of $1.62(95 \% \mathrm{Cl} 1.32$ to 1.98) after adjustment for age, sex, daily smoking, physical activity, education, socio-economic status, family history of asthma, and body mass index (BMI). The positive association was consistent across age $(<40 /$ $\geq 40$ years), sex (men/women), family history of asthma (yes/no) and BMI subgroups $\left(<25 / \geq 25 \mathrm{~kg} / \mathrm{m}^{2}\right)$.

Conclusions Intake of cod liver oil with high vitamin A content was significantly associated with increased incidence of adult-onset asthma.

\section{INTRODUCTION}

The relationship between vitamin D intake and asthma development has been vigorously debated for several years. Wjst and Dold claim that asthma is caused by vitamin D supplementation, ${ }^{1}$ while Litonjua and Weiss state that low vitamin D intake is the cause of the global asthma epidemic. ${ }^{2}$ The assertion that vitamin D intake may be a risk factor for development of asthma and allergic disease is supported by a few epidemiologic studies from the Nordic countries. ${ }^{3}$ Several other studies, however, suggest that vitamin $\mathrm{D}$ intake may be protective against asthma and allergy. ${ }^{5-8}$

The type of food or supplement with vitamin D may be crucial for the discrepancies among studies, as the ingested item may contain other elements apart from vitamin D. Vitamin D can be provided by diverse sources, among which cod liver oil has been an important supply of vitamin D, particularly
Key messages

What is the key question?

- Is cod liver oil intake associated with an increased incidence of asthma?

What is the bottom line?

- Cod liver oil containing a high concentration of vitamin A was significantly associated with an increased risk of incident asthma in Norwegian adults.

\section{Why read on?}

- This is the first large prospective study evaluating the association of cod liver oil intake with asthma development.

in the Nordic countries. ${ }^{9}$ Cod liver oil also contains other fat-soluble components such as vitamin A, and high vitamin A status has been linked to an increased risk of several chronic diseases. ${ }^{10-13}$ To date, the association between cod liver oil intake and asthma development remains unclear.

In Norway, the cod liver oil formula contained a high concentration of vitamin A $(1000 \mu \mathrm{g}$ per $5 \mathrm{ml}$ ) before 1999. Because of the possible adverse effect of excessive vitamin A intake on bone mineral density and fracture risk, ${ }^{14}$ it was gradually reduced to the current concentration $(250 \mu \mathrm{g}$ per $5 \mathrm{ml}$ ) between 1999 and 2002. ${ }^{15}$ We conducted a study among adults in Norway who participated in the Nord-Trøndelag Health Study (HUNT) in 1995-1997 and were followed up to 2006-2008, for an average of 11 years. This provided us a unique opportunity to evaluate the association between intake of cod liver oil with high vitamin A concentration and risk of adult-onset asthma.

\section{SUBJECTS, MATERIALS AND METHODS \\ Study design}

HUNT is the largest population health survey in Norway. ${ }^{16}$ The adult part of the HUNT invited all inhabitants aged 19 years or older in the county of Nord-Trøndelag in the three separate surveys: HUNT 1 (1984-1986), HUNT 2 (1995-1997) and HUNT 3 (2006-2008). In the current study, we used data from HUNT 2 and HUNT 3. HUNT 2 invited about 93000 adults in 1995-1997, and 65215 subjects participated (response rate 70\%). Among them, 57\% $(\mathrm{n}=37059)$ took part in HUNT 3 in 2006-2008. We established a cohort 
population that included all subjects who participated in HUNT 2 and HUNT 3 and were less than 65 years of age in HUNT 3 $(n=25616) .{ }^{17}$ This cohort was set up with an intention to study a range of associations between environmental factors and asthma development. The upper age limit ( $<65$ years) was set to reduce the possibility of misclassification of newly diagnosed asthma and chronic obstructive pulmonary disease (COPD).

The cohort population answered the same question regarding asthma in HUNT 2 and HUNT 3, that is, 'Do you have or have you had asthma?' Excluding asthma in HUNT 2 and missing information on asthma in either HUNT 2 or HUNT 3 $(n=2050), 23566$ subjects were left in the cohort who were free from asthma at baseline. Participants who reported no asthma in HUNT 2 but reported asthma in HUNT 3 were regarded as incident asthma cases over an average 11-year follow-up. A stricter asthma definition was also used, that is, participants who were free from wheeze and asthma at baseline reported asthma at follow-up in combination with use of asthma medications (eg, inhaled corticosteroids and/or $\beta 2$-agonists); participants who were free from wheeze and asthma both at baseline and at follow-up served as the reference group. Use of asthma medications provides medical validation of the incident cases, since the asthma diagnosis is confirmed by a doctor when asthma medications are prescribed to adult patients in Norway.

\section{Cod liver oil intake at baseline}

Total months of daily use of cod liver oil during the past 12 months were recorded in the HUNT 2 questionnaires. Regular cod liver oil intake was defined as a daily intake for $\geq 1$ month (yes/no). Among the 23566 subjects free of asthma, 17528 subjects had complete data on cod liver oil intake at baseline and they were included in the final analysis.

\section{Other baseline variables}

Other important baseline variables were collected by questionnaires in HUNT 2. These covariates were categorised as: age (19-29, 30-39, 40-49, and 50-55 years), sex, daily smoker (yes/no), average hours of light physical activity per week $(<1$, $1-2$ and $\geq 3 \mathrm{~h}$ ), years of education $(<10,10-12$ and $\geq 13$ years), social benefit recipient (yes/no), economic difficulties (yes/no), and family history of asthma (yes/no). Social benefit recipients were those who reported receiving any of the public welfare benefits. Economic difficulties referred to those who had difficulties to meet the costs of food, transportation or housing. Body weight and height in HUNT 2 were measured by health professionals. Body mass index (BMI, $\mathrm{kg} / \mathrm{m}^{2}$ ) was grouped into $<25.0,25.0-29.9$ and $\geq 30.0 \mathrm{~kg} / \mathrm{m}^{2}$ categories according to the recommendations of the WHO. ${ }^{18}$ Specific information on vitamin D supplementation was collected in the HUNT 2 questionnaires for women only. Information on use of multivitamins was asked in the HUNT 2 questionnaires for both women and men.

\section{Statistical analysis}

The associations of baseline characteristics with cod liver oil intake were studied by using logistic regression analyses, which yielded OR and 95\% CI. The cumulative incidence of asthma over the 11-year follow-up was compared between subjects who did and did not consume cod liver oil daily for $\geq 1$ month. The association of cod liver oil intake and incident asthma was estimated in multivariable logistic regression model I, including age (19-29, 30-39, 40-49 and 50-55 years), sex (men/women), daily smoking (yes, no and unknown), physical activity $(<1,1-$ $2, \geq 3 \mathrm{~h}$ and unknown), education $(<10,10-12, \geq 13$ years and unknown), social benefit (yes, no and unknown), economic difficulties (yes, no and unknown), family history of asthma (yes, no and unknown), and BMI categories (<25.0, 25.0-29.9, $\geq 30.0 \mathrm{~kg} / \mathrm{m}^{2}$ and unknown) at baseline as covariates. Model II adjusted for vitamin D supplementation (yes, no and unknown) in addition to the covariates in model I among women (but not men). Model III adjusted for use of multivitamins (yes, no and unknown) in addition to the covariates in model I. Cod liver oil intake (total months of daily intake) was also analysed as a continuous variable. Furthermore, we evaluated the association between cod liver oil intake and incident asthma in subgroups stratified by age ( $<40$ vs $\geq 40$ years), sex (men vs women),

Table 1 Baseline characteristics in association with cod liver oil intake, the HUNT study, 1995-1997 to 2006-2008 ( $n=17$ 528)

\begin{tabular}{|c|c|c|c|c|}
\hline & \multirow[b]{2}{*}{ No. of subjects } & \multicolumn{2}{|c|}{$\begin{array}{l}\text { Cod liver oil } \\
\text { daily intake } \\
\geq 1 \text { month in } \\
\text { past year }\end{array}$} & \multirow[b]{2}{*}{ Crude OR $(95 \% \mathrm{Cl})$} \\
\hline & & $\mathrm{n}$ & $\%$ & \\
\hline Total & 17528 & 3076 & 17.5 & \\
\hline \multicolumn{5}{|c|}{ Age at baseline (years) } \\
\hline $19-29$ & 2805 & 345 & 12.3 & 1.00 (reference) \\
\hline $30-39$ & 5424 & 774 & 14.3 & 1.19 (1.04 to 1.36$)$ \\
\hline $40-49$ & 6701 & 1309 & 19.5 & 1.73 (1.52 to 1.97$)$ \\
\hline $50-55$ & 2598 & 648 & 24.9 & 2.37 (2.05 to 2.74$)$ \\
\hline \multicolumn{5}{|l|}{ Sex } \\
\hline Women & 9786 & 1937 & 19.8 & 1.00 (reference) \\
\hline Men & 7742 & 1139 & 14.7 & 0.70 (0.65 to 0.76$)$ \\
\hline \multicolumn{5}{|l|}{ Daily smokers } \\
\hline No & 11855 & 2195 & 18.5 & 1.00 (reference) \\
\hline Yes & 4761 & 702 & 14.7 & 0.76 (0.69 to 0.83$)$ \\
\hline Unknown & 912 & & & \\
\hline \multicolumn{5}{|c|}{ Physical activity (h/week) } \\
\hline$<1$ & 3810 & 549 & 14.4 & 1.00 (reference) \\
\hline $1-2$ & 6420 & 1151 & 17.9 & 1.30 (1.16 to 1.45$)$ \\
\hline$\geq 3$ & 5569 & 1069 & 19.2 & 1.41 (1.26 to 1.58$)$ \\
\hline Unknown & 1729 & & & \\
\hline \multicolumn{5}{|l|}{ Education (years) } \\
\hline$<10$ & 3203 & 567 & 17.7 & 1.00 (reference) \\
\hline $10-12$ & 9365 & 1416 & 15.1 & 0.83 (0.74 to 0.92$)$ \\
\hline$\geq 13$ & 4846 & 1074 & 22.2 & 1.32 (1.18 to 1.48$)$ \\
\hline Unknown & 114 & & & \\
\hline \multicolumn{5}{|l|}{ Social benefit } \\
\hline Non-recipient & 13221 & 2222 & 16.8 & 1.00 (reference) \\
\hline Recipient & 3213 & 670 & 20.9 & 1.30 (1.18 to 1.44$)$ \\
\hline Unknown & 1094 & & & \\
\hline \multicolumn{5}{|c|}{ Economic difficulties } \\
\hline No & 11863 & 2203 & 18.6 & 1.00 (reference) \\
\hline Yes & 5468 & 838 & 15.3 & 0.79 (0.73 to 0.87$)$ \\
\hline Unknown & 197 & & & \\
\hline \multicolumn{5}{|c|}{ Family history of asthma } \\
\hline No & 13606 & 2365 & 17.4 & 1.00 (reference) \\
\hline Yes & 2926 & 535 & 18.3 & 1.06 (0.96 to 1.18$)$ \\
\hline Unknown & 996 & & & \\
\hline \multicolumn{5}{|c|}{ Body mass index $\left(\mathrm{kg} / \mathrm{m}^{2}\right)$} \\
\hline$<25.0$ & 8289 & 1503 & 18.1 & 1.00 (reference) \\
\hline $25.0-29.9$ & 7251 & 1271 & 17.5 & 0.96 (0.88 to 1.04$)$ \\
\hline$\geq 30.0$ & 1955 & 296 & 15.1 & 0.81 (0.70 to 0.92 ) \\
\hline Unknown & 33 & & & \\
\hline
\end{tabular}


family history of asthma (yes vs no), BMI ( $<25.0$ vs $\geq 25.0 \mathrm{~kg}$ ) $\mathrm{m}^{2}$ ), daily smoking (yes vs no), physical activity ( $<3$ vs $\geq 3 \mathrm{~h}$ ), education ( $<13$ vs $\geq 13$ years) and socioeconomic status (yes vs no). Due to a large amount of missing data on cod liver oil intake, we performed sensitivity analyses to address the potential bias by missing data. Two extreme scenarios were tested: all missing values $(n=6038)$ were regarded as either cod liver oil daily intake for $\geq 1$ month 'yes' or 'no' group. Multiple imputations of the missing data on cod liver oil and other baseline characteristics were also performed with similar analytic results (not presented). Another sensitivity analysis was performed in 15424 subjects by using the stricter definition of asthma to test the robustness of our results. All statistical analyses were performed with STATA, release V.12.0. ${ }^{19}$

\section{Ethics}

The study was approved by the Regional Committee for Medical Research Ethics. All participants gave their informed consent on participation in HUNT, linkage to previous HUNT surveys and specific registries.

\section{RESULTS}

Of the 17528 subjects, 18\% $(n=3076)$ consumed cod liver oil daily for $\geq 1$ month during the year prior to baseline. Subjects older in age, those with more hours of physical activity, more years of education, or those who received social benefits were more likely to consume cod liver oil than others (table 1), whereas men, smokers, subjects with economic difficulties or those with obesity were less likely to use cod liver oil. Those who took cod liver oil regularly (daily intake for $\geq 1$ month) compared with those who did not were also more likely to be consumers of multivitamins $(24 \%$ vs $3 \%)$ and users of vitamin D supplement among women (28\% vs $11 \%)$.

The cumulative incidence of asthma over the 11-year follow-up was $4.4 \%$ among people who regularly consumed cod liver oil compared with $2.9 \%$ among people who did not (table 2). After adjustment for baseline characteristics (model I), cod liver oil consumption was significantly associated with an increased incidence of asthma (OR 1.62; 95\% CI 1.32 to 1.98), and the ORs were 1.51 (1.06 to 2.15 ) and 1.68 (1.31 to 2.16) among men and women, respectively. In addition, each 1 month daily intake of cod liver oil was significantly associated with incident asthma (table 2). After additional adjustment for vitamin D supplementation (model II) among women, the positive association of cod liver oil intake and incident asthma remained (OR $1.67 ; 1.29$ to 2.15$)$. In contrast to the cod liver oil findings, vitamin $\mathrm{D}$ supplementation was not significantly associated with incident asthma among women (OR 1.05; 0.76 to 1.44). Additional adjustment for use of multivitamins (model III) yielded an attenuated but significant OR for cod liver oil intake in the total population (table 2).

Cod liver oil intake was associated with an increased asthma risk in several subgroup analyses: people $<40$ versus $\geq 40$ years of age, those with family history of asthma versus those without, and those who were non-overweight versus overweight (table 3 ). The positive association was also consistent in other subgroup analyses stratified by daily smoking (OR 1.89 (1.35 to 2.64) for yes vs OR 1.51 (1.16 to 1.97$)$ for no), physical activity (OR 1.64 (1.25 to 2.14 ) for $<3 \mathrm{~h}$ vs OR 1.36 (0.92 to 2.00 ) for $\geq 3 \mathrm{~h}$ ), education (OR 1.59 (1.26 to 2.02) for $<13$ years vs OR $1.76(1.15$ to 2.68 ) for $\geq 13$ years) and economic difficulties (OR 1.56 (1.12 to 2.16 ) for yes vs OR 1.64 (1.26 to 2.14) for no) using model I. Additional adjustment for use of multivitamins (model III) did not significantly alter the results (data not shown).

When the missing group was merged with those who did not consume cod liver oil regularly, the association between cod liver oil intake and incident asthma remained significant after adjustment for baseline characteristics (OR 1.38 (1.13 to 1.68), table 4). When the missing group was pooled with those who consumed cod liver oil regularly, the adjusted OR for cod liver oil intake was 1.68 (1.43 to 1.96). Analysis with an additional adjustment for use of multivitamins showed similar results (not presented).

Using the stricter definition for asthma $(n=15424)$, the positive association between cod liver oil intake and incident asthma was generally strengthened with an adjusted OR being 1.84 (1.43 to 2.37), and the association was consistent in men and women (table 5). Additional adjustment for intake of multivitamins and vitamin D supplement among women made no substantial changes to the results (table 5). Restricting this analysis

Table 2 The association of baseline cod liver oil intake with cumulative incidence of asthma over 11-year follow-up period, the HUNT study, 1995-1997 to 2006-2008 ( $n=17$ 528)

\begin{tabular}{|c|c|c|c|c|c|c|c|}
\hline $\begin{array}{l}\text { Cod liver oil daily intake } \\
\geq 1 \text { month past year }\end{array}$ & No. & Cases & $\%$ & Crude OR $(95 \% \mathrm{CI})$ & $\begin{array}{l}\text { Adjusted OR }(95 \% \mathrm{CI}) \\
\text { Model I* }\end{array}$ & $\begin{array}{l}\text { Adjusted OR }(95 \% \mathrm{Cl}) \\
\text { Model IIt }\end{array}$ & $\begin{array}{l}\text { Adjusted OR }(95 \% \mathrm{Cl}) \\
\text { Model III‡ }\end{array}$ \\
\hline \multicolumn{8}{|l|}{ Total $(n=17528)$} \\
\hline No & 14452 & 423 & 2.9 & 1.00 (reference) & 1.00 (reference) & & 1.00 (reference) \\
\hline Yes & 3076 & 135 & 4.4 & 1.52 (1.25 to 1.86$)$ & 1.62 (1.32 to 1.98$)$ & & 1.45 (1.14 to 1.84$)$ \\
\hline Each 1 month intake & & & & 1.03 (1.01 to 1.06$)$ & 1.04 (1.02 to 1.07$)$ & & 1.03 (1.00 to 1.05$)$ \\
\hline \multicolumn{8}{|l|}{ Men $(n=7742)$} \\
\hline No & 6603 & 164 & 2.5 & 1.00 (reference) & 1.00 (reference) & & 1.00 (reference) \\
\hline Yes & 1139 & 42 & 3.7 & 1.50 (1.06 to 2.12$)$ & 1.51 (1.06 to 2.15$)$ & & $1.43(0.94$ to 2.16$)$ \\
\hline Each 1 month intake & & & & $1.03(0.99$ to 1.07$)$ & $1.03(0.99$ to 1.08$)$ & & 1.02 (0.98 to 1.07$)$ \\
\hline \multicolumn{8}{|l|}{ Women $(n=9786)$} \\
\hline No & 7849 & 259 & 3.3 & 1.00 (reference) & 1.00 (reference) & 1.00 (reference) & 1.00 (reference) \\
\hline Yes & 1937 & 93 & 4.8 & 1.48 (1.16 to 1.88$)$ & 1.68 (1.31 to 2.16$)$ & 1.67 (1.29 to 2.15$)$ & 1.47 (1.10 to 1.97$)$ \\
\hline Each 1 month intake & & & & 1.03 (1.00 to 1.06$)$ & 1.05 (1.02 to 1.08$)$ & 1.04 (1.02 to 1.08$)$ & 1.03 (1.00 to 1.06$)$ \\
\hline
\end{tabular}


Table 3 Cod liver oil intake in association with cumulative incidence of asthma over 11-year follow-up period stratified by age, family history of asthma or BMI, the HUNT study, 1995-1997 to 2006-2008 ( $n=17$ 528)

\begin{tabular}{|c|c|c|c|c|c|c|}
\hline $\begin{array}{l}\text { Cod liver oil daily intake } \\
\geq 1 \text { month past year }\end{array}$ & $\begin{array}{l}\text { No. of } \\
\text { subjects }\end{array}$ & $\begin{array}{l}\text { Cum. incidence of } \\
\text { asthma (\%) }\end{array}$ & $\begin{array}{l}\text { Adjusted OR }(95 \% \mathrm{Cl}) \\
{ }^{*} \text { Model I }\end{array}$ & $\begin{array}{l}\text { No. of } \\
\text { subjects }\end{array}$ & $\begin{array}{l}\text { Cum. incidence of } \\
\text { asthma (\%) }\end{array}$ & $\begin{array}{l}\text { Adjusted OR }(95 \% \mathrm{Cl}) \\
\text { Model I* }\end{array}$ \\
\hline & \multicolumn{3}{|c|}{ Age $<40$ years } & \multicolumn{3}{|c|}{ Age $\geq 40$ years } \\
\hline No & 7110 & 3.1 & 1.00 (reference) & 7342 & 2.8 & 1.00 (reference) \\
\hline Yes & 1119 & 4.7 & 1.62 (1.18 to 2.22$)$ & 1957 & 4.2 & 1.63 (1.25 to 2.13$)$ \\
\hline \multirow[t]{2}{*}{ Each 1 month intake } & & & $1.04(1.00$ to 1.08$)$ & & & 1.04 (1.01 to 1.08$)$ \\
\hline & \multicolumn{3}{|c|}{ No family history of asthmat } & \multicolumn{3}{|c|}{ With family history of asthmat } \\
\hline No & 11241 & 2.3 & 1.00 (reference) & 2391 & 5.4 & 1.00 (reference) \\
\hline Yes & 2365 & 3.3 & 1.63 (1.25 to 2.12$)$ & 535 & 8.6 & 1.68 (1.16 to 2.41$)$ \\
\hline \multirow[t]{2}{*}{ Each 1 month intake } & & & 1.05 (1.02 to 1.08$)$ & & & $1.03(0.99$ to 1.08$)$ \\
\hline & \multicolumn{3}{|c|}{$\mathrm{BMI}<25.0 \mathrm{~kg} / \mathrm{m}^{2} \ddagger$} & \multicolumn{3}{|c|}{$\mathrm{BMI} \geq 25.0 \mathrm{~kg} / \mathrm{m}^{2} \ddagger$} \\
\hline No & 6786 & 2.3 & 1.00 (reference) & 7639 & 3.5 & 1.00 (reference) \\
\hline Yes & 1503 & 3.8 & 1.98 (1.44 to 2.72$)$ & 1567 & 5.0 & 1.40 (1.08 to 1.83$)$ \\
\hline Each 1 month intake & & & 1.06 (1.02 to 1.09$)$ & & & $1.03(1.00$ to 1.06$)$ \\
\hline
\end{tabular}

to subjects who never reported COPD $(n=15324)$, the association of cod liver oil intake with incident asthma remained after adjustment for baseline characteristics (OR 1.92; 1.47 to 2.50).

\section{DISCUSSION}

Our study demonstrated that intake of cod liver oil was associated with an increased incidence of asthma among adults. This positive association was consistently shown in subgroups stratified by age, sex, family history of asthma and BMI.

The findings in our prospective cohort study are consistent with two previous cross-sectional studies which found a positive association between cod liver oil consumption and asthma prevalence. $^{2021}$ Our results may also explain the inconsistent findings of previous studies on vitamin D intake and allergic disease-namely, different vitamin $\mathrm{D}$ product may be the explanation for the inconsistency. While others reported an inverse association, ${ }^{5-8}$ two Nordic studies demonstrated a

Table 4 Sensitivity analyses including missing data ( $n=23566$ ): the association of baseline cod liver oil intake with cumulative incidence of asthma over 11-year follow-up period, the HUNT Study, 1995-1997 to 2006-2008

\begin{tabular}{|c|c|c|c|c|c|}
\hline $\begin{array}{l}\text { Cod liver oil daily } \\
\text { intake } \geq 1 \text { month } \\
\text { past year }\end{array}$ & No. & Cases & $\%$ & $\begin{array}{l}\text { Crude OR } \\
(95 \% \mathrm{Cl})\end{array}$ & $\begin{array}{l}\text { Adjusted OR } \\
(95 \% \mathrm{CI}) \\
\text { Model I* }\end{array}$ \\
\hline \multicolumn{6}{|c|}{ Missing regarded as intake 'no' } \\
\hline No & 20490 & 692 & 3.4 & $\begin{array}{l}1.00 \\
\text { (reference) }\end{array}$ & $\begin{array}{l}1.00 \\
\text { (reference) }\end{array}$ \\
\hline Yes & 3076 & 135 & 4.4 & $\begin{array}{l}1.31 \text { (1.09 to } \\
1.59)\end{array}$ & $\begin{array}{l}1.38(1.13 \text { to } \\
1.68)\end{array}$ \\
\hline \multicolumn{6}{|c|}{ Missing regarded as intake 'yes' } \\
\hline No & 14452 & 423 & 2.9 & $\begin{array}{l}1.00 \\
\text { (reference) }\end{array}$ & $\begin{array}{l}1.00 \\
\text { (reference) }\end{array}$ \\
\hline Yes & 9114 & 404 & 4.4 & $\begin{array}{l}1.54(1.34 \text { to } \\
1.77)\end{array}$ & $\begin{array}{l}1.68(1.43 \text { to } \\
1.96)\end{array}$ \\
\hline
\end{tabular}

*Model I adjusted for age, sex, daily smoking, physical activity, education, social benefit, economic difficulties, family history of asthma and body mass index. HUNT, Nord-Trøndelag Health Study. positive association between vitamin $\mathrm{D}$ intake and allergic disease. $^{34}$

Content of vitamin D in the formula of cod liver oil in Norway has been kept the same as the daily recommendation (400 IU per $5 \mathrm{ml}$ ). Our latest work in a nested case-control study from the same cohort population did not provide any evidence that higher serum 25-hydroxyvitamin D level was associated with higher risk of incident asthma. ${ }^{22}$ In addition to vitamin $\mathrm{D}$, cod liver oil contains vitamin $\mathrm{A}$, and the vitamin $\mathrm{A}$ content was high in the previous formula before $1999(1000 \mu \mathrm{g}$ per $5 \mathrm{ml}$ ). Compared with the current daily recommendation of vitamin $A$, this earlier formulation had $143 \%$ and $111 \%$ of what is needed by women and men, respectively. A high concentration of vitamin A in cod liver oil may have played a role for the increased ORs of asthma observed in our study and the two aforementioned cross-sectional studies on asthma prevalence. $^{20} 21$ With regard to the observed adverse impact of 'vitamin D' in the two Nordic studies, ${ }^{3}{ }^{4}$ there was a possibility that other elements in the vitamin D product might have been responsible for the increased allergy risk. In a Finnish study, ${ }^{4}$ the increased risk of allergy was suspected to be due to the high dose of vitamin D intake (at least 2000 IU per day). The authors did speculate though that some unmeasured determinants in the vitamin $\mathrm{D}$ product might be accountable for the increased risk, but there was no additional information about the vitamin D product in this report. In a Swedish study, ${ }^{3}$ all children were provided daily with five drops of sunflower seed oil containing both vitamin D (400 IU) and a high dose of vitamin A (1000 IU). The effect of vitamin A was not taken into account, nor discussed, when the authors reported the association of vitamin $\mathrm{D}$ with allergy risk and children.

Although high vitamin A status has been linked to increased risks of several chronic diseases, ${ }^{10-13}$ the relation between vitamin A and asthma has not extensively been studied. Cross-sectional studies showed an inverse association between vitamin A intake or serum concentration and asthma, ${ }^{23}$ while a recent randomised trial reported a null finding. ${ }^{24}$ Nonetheless, it has been documented that vitamin A accumulates in the lung. Upon exposure to triggers of asthma, a high concentration of vitamin A metabolites may produce an acute, localised form of 
Table 5 Sensitivity analysis using a stricter definition for asthma* $(n=15424)$ : the association of baseline cod liver oil intake with cumulative incidence of asthma over 11-year follow-up period, the HUNT Study, 1995-1997 to 2006-2008

\begin{tabular}{|c|c|c|c|c|c|c|c|}
\hline $\begin{array}{l}\text { Cod liver oil daily intake } \\
\geq 1 \text { month past year }\end{array}$ & No. & Cases & $\%$ & Crude OR $(95 \% \mathrm{Cl})$ & $\begin{array}{l}\text { Adjusted OR }(95 \% \mathrm{Cl}) \\
\text { Model It }\end{array}$ & $\begin{array}{l}\text { Adjusted OR (95\% Cl) } \\
\text { Model II }\end{array}$ & $\begin{array}{l}\text { Adjusted OR }(95 \% \mathrm{Cl}) \\
\text { Model III }\end{array}$ \\
\hline \multicolumn{8}{|l|}{ Total $(n=15424)$} \\
\hline No & 12796 & 256 & 2.0 & 1.00 (reference) & 1.00 (reference) & & 1.00 (reference) \\
\hline Yes & 2628 & 87 & 3.3 & 1.68 (1.31 to 2.15$)$ & 1.84 (1.43 to 2.37 ) & & 1.59 (1.18 to 2.15$)$ \\
\hline Each 1 month intake & & & & 1.05 (1.02 to 1.07 ) & 1.04 (1.02 to 1.07 ) & & 1.04 (1.00 to 1.07 ) \\
\hline \multicolumn{8}{|l|}{ Men $(n=6797)$} \\
\hline No & 5830 & 100 & 1.7 & 1.00 (reference) & 1.00 (reference) & & 1.00 (reference) \\
\hline Yes & 967 & 26 & 2.7 & 1.58 (1.02 to 2.45$)$ & 1.66 (1.06 to 2.60$)$ & & 1.63 (0.97 to 2.72 ) \\
\hline Each 1 month intake & & & & 1.03 (0.98 to 1.08 ) & 1.04 (0.98 to 1.09 ) & & 1.03 (0.97 to 1.09 ) \\
\hline \multicolumn{8}{|l|}{ Women $(n=8627)$} \\
\hline No & 6966 & 156 & 2.2 & 1.00 (reference) & 1.00 (reference) & 1.00 (reference) & 1.00 (reference) \\
\hline Yes & 1661 & 61 & 3.7 & 1.66 (1.23 to 2.25$)$ & 1.97 (1.44 to 2.69$)$ & 1.93 (1.41 to 2.66$)$ & 1.60 (1.10 to 2.31$)$ \\
\hline Each 1 month intake & & & & 1.05 (1.01 to 1.08$)$ & 1.07 (1.03 to 1.11$)$ & 1.07 (1.03 to 1.10$)$ & 1.04 (1.00 to 1.08$)$ \\
\hline \multicolumn{8}{|c|}{$\begin{array}{l}\text { *Stricter definition for asthma: participants who were free from wheeze and asthma at baseline reported asthma at follow-up in combination with use of asthma medication; } \\
\text { participants who were free from wheeze and asthma at baseline and at follow-up served as the reference group. } \\
\text { †Model I adjusted for age, sex, daily smoking, physical activity, education, social benefit, economic difficulties, family history of asthma and body mass index. } \\
\text { fModel II adjusted for vitamin D supplementation in addition to the covariates in model I among women. } \\
\text { SModel III adjusted for use of multivitamins in addition to the covariates in model I. } \\
\text { HUNT, Nord-Trøndelag Health Study. }\end{array}$} \\
\hline
\end{tabular}

vitamin A intoxication which is recognised as 'asthma'. ${ }^{25}$ Research also shows that vitamin A may interact with vitamin $\mathrm{D}$, possibly at the receptor level. A nested case-control study firstly demonstrated an inverse association between high vitamin D status and risk of colorectal cancer, but the association disappeared in subjects who had high vitamin A intake. ${ }^{26}$ This may help to explain the inconsistent findings on vitamin D intake and asthma and allergy in previous studies, in which some of the vitamin D products may have contained vitamin A.

To our knowledge, the current study is the first large prospective study evaluating the association of cod liver oil with asthma development. It partially explains the inconsistent findings of previous studies on vitamin D intake and asthma and allergic disease-namely, that while at least part of the adverse impact of 'vitamin D' on asthma/allergy risk may actually be due to vitamin A. Our results were consistent across age, sex, family history of asthma and BMI. The high dose of vitamin $\mathrm{A}$ in a previous formula of cod liver oil in Norway provided a unique opportunity for us to assess the potential increased risk of asthma among cod liver oil consumers. Although the high content was reduced to the current $250 \mu \mathrm{g}$ per $5 \mathrm{ml}$ since 2002 , the assumed long-term use of vitamin $\mathrm{A}$ in a high dose may have a carryover effect on disease risk. We were also able to adjust for a wide range of possible confounding factors and evaluate the role of cod liver oil intake while taking vitamin D supplementation and use of multivitamins into consideration. Vitamin D supplementation showed no important impact on the association between cod liver oil intake and incident asthma among women. Use of multivitamins attenuated the association of incident asthma with cod liver oil intake, but it did not significantly alter the positive association.

Our study was limited by lack of objective measure of vitamin $A$ in the body. One would argue that there might be other elements in cod liver oil increasing the risk of asthma. In addition to vitamin A, cod liver oil in Norway contains vitamin $\mathrm{E}$ and $\omega-3$ fatty acids. However, the contents of vitamin $E$ and $\omega-3$ fatty acids in the cod liver oil product in Norway have been in normal ranges relative to the daily needs. Besides, epidemiological evidence generally shows a lack of or inverse association of vitamin E with asthma. ${ }^{23} 2728$ Likewise, systematic reviews of randomised controlled trials demonstrate either no effect or a protective effect of $\omega-3$ fatty acids on the development of asthma and allergy. ${ }^{29} 30$ In addition to the high content of vitamin $\mathrm{A}$ in cod liver oil, the traditional Norwegian diets are rich in other sources of vitamin A, for example, animal liver and dairy products. ${ }^{15}$ Unfortunately, we lacked detailed information on dietary sources which may contain vitamin A and provitamin A. Another limitation of the present study was the substantial missing information on cod liver oil intake. However, sensitivity analysis and multiple imputations did not reveal that potential bias caused by missing information would alter our conclusions. Moreover, self-reported asthma may cause classification bias, although previous studies suggest that the validity and reliability of self-reported asthma are acceptable. ${ }^{31} 32$ Nevertheless, the sensitivity analysis by using a stricter asthma definition (a medical validation of the incident cases) demonstrated the robustness of our findings.

In summary, we found that intake of cod liver oil containing a high concentration of vitamin A was significantly associated with an increased risk of asthma in Norwegian adults. This finding should not be generalised to the current formula of cod liver oil, as vitamin A has been kept at a lower concentration $(250 \mathrm{~g}$ per $5 \mathrm{ml}$ ) since 2002, but further studies are needed to evaluate the association of cod liver oil in the current formula with asthma development in adults and children.

Acknowledgements The Nord-Trøndelag Health Study (the HUNT study) is a collaboration between the HUNT Research Centre (Faculty of Medicine, Norwegian University of Science and Technology NTNU), Nord-Trøndelag County Council and the Norwegian Institute of Public Health. We especially acknowledge Ben Brumpton for performing multiple imputations.

Contributors XMM was the principal investigator of the study. XMM, AL, YC and CAC contributed to the study design. XMM and AL were responsible for data collection. XMM conducted statistical analyses, interpreted results and wrote the initial draft of the manuscript. AL, YC and CAC participated in the data interpretation and contributed to the final draft of the manuscript with important intellectual content.

Funding This study was supported by the Research Council of Norway (project no. 201895/V50). The Lung Study in HUNT 2 and HUNT 3 received funding from 
AstraZeneca Norway. None of the funding sources were involved in any aspect of the study design, conduct, analysis, interpretation of data or writing the report.

Competing interests None.

Provenance and peer review Not commissioned; externally peer reviewed.

\section{REFERENCES}

1 Wjst $\mathrm{M}$, Dold $\mathrm{S}$. Genes, factor $\mathrm{X}$, and allergens: what causes allergic diseases? Allergy 1999;54:757-9.

2 Litonjua AA, Weiss ST. Is vitamin D deficiency to blame for the asthma epidemic? J Allergy Clin Immunol 2007;120:1031-5.

3 Back O, Blomquist HK, Hernell O, et al. Does vitamin D intake during infancy promote the development of atopic allergy? Acta Derm Venereol 2009;89:28-32.

4 Hypponen E, Sovio U, Wjst M, et al. Infant vitamin D supplementation and allergic conditions in adulthood: northern Finland birth cohort 1966. Ann N Y Acad Sci 2004; 1037:84-95.

5 Camargo CA Jr, Rifas-Shiman SL, Litonjua AA, et al. Maternal intake of vitamin D during pregnancy and risk of recurrent wheeze in children at 3 y of age. Am J Clin Nutr 2007:85:788-95.

6 Devereux G, Litonjua AA, Turner SW, et al. Maternal vitamin D intake during pregnancy and early childhood wheezing. Am J Clin Nutr 2007;85:853-9.

7 Erkkola M, Kaila M, Nwaru Bl, et al. Maternal vitamin D intake during pregnancy is inversely associated with asthma and allergic rhinitis in 5-year-old children. Clin Exp Allergy 2009:39:875-82.

8 Miyake $Y$, Sasaki S, Tanaka $K$, et al. Dairy food, calcium and vitamin D intake in pregnancy, and wheeze and eczema in infants. Eur Respir J 2010;35:1228-34.

9 Rajakumar K. Vitamin D, cod-liver oil, sunlight, and rickets: a historical perspective. Pediatrics 2003; 112:e132-5.

10 Feskanich $D$, Singh V, Willett WC, et al. Vitamin A intake and hip fractures among postmenopausal women. JAMA 2002;287:47-54.

11 Michaelsson $\mathrm{K}$, Lithell $\mathrm{H}$, Vessby $B$, et al. Serum retinol levels and the risk of fracture. N Engl J Med 2003;348:287-94.

12 Miyazaki M, Doi Y, Ikeda F, et al. Dietary vitamin A intake and incidence of gastric cancer in a general Japanese population: the Hisayama Study. Gastric Cancer. Published Online First: 23 September 2011. doi: 10.1007/s10120-011-0092-7

13 Mondul AM, Watters JL, Mannisto S, et al. Serum retinol and risk of prostate cancer. Am J Epidemiol 2011;173:813-21.

14 Melhus H, Michaelsson K, Kindmark A, et al. Excessive dietary intake of vitamin A is associated with reduced bone mineral density and increased risk for hip fracture. Ann Intern Med 1998:129:770-8.

15 Forsmo S, Fjeldbo SK, Langhammer A. Childhood cod liver oil consumption and bone mineral density in a population-based cohort of peri- and postmenopausal women: the Nord-Trondelag Health Study. Am J Epidemiol 2008;167:406-11.
16 Holmen J. The Nord-Trøndelag Health Study 1995-97 (HUNT 2): objectives, contents, methods and participation. Norsk Epidemiologi 2003;13:19-32.

17 Mai XM, Chen Y, Camargo CA Jr, et al. Cross-sectional and prospective cohort study of serum 25-hydroxyvitamin D level and obesity in adults: the HUNT Study. Am J Epidemiol 2012:175:1029-36.

18 World Health Organization. Obesity: preventing and managing the global epidemic. Report of a WHO consultation. Geneva: World Health Organization; 2004.

19 StataCorp LP. STATA, release 12.0. College Station, Texas: StataCorp LP, 2011.

20 Hughes AM, Lucas RM, Ponsonby AL, et al. The role of latitude, ultraviolet radiation exposure and vitamin $\mathrm{D}$ in childhood asthma and hayfever: an Australian multicenter study. Pediatr Allergy Immunol 2011;22:327-33.

21 Laerum BN, Wentzel-Larsen T, Gulsvik A, et al. Relationship of fish and cod oil intake with adult asthma. Clin Exp Allergy 2007;37:1616-23.

22 Mai XM, Langhammer A, Camargo CA Jr, et al. Serum 25-hydroxyvitamin D levels and incident asthma in adults - the HUNT Study. Am J Epidemiol 2012, in press.

23 Allen S, Britton JR, Leonardi-Bee JA. Association between antioxidant vitamins and asthma outcome measures: systematic review and meta-analysis. Thorax 2009;64:610-19.

24 Checkley W, West KP Jr, Wise RA, et al. Supplementation with vitamin A early in life and subsequent risk of asthma. Eur Respir J 2011;38:1310-19.

25 Mawson AR. Could bronchial asthma be an endogenous, pulmonary expression of retinoid intoxication? Front Biosci 2001;6:D973-85

26 Jenab M, Bueno-de-Mesquita HB, Ferrari $\mathrm{P}$, et al. Association between pre-diagnostic circulating vitamin $D$ concentration and risk of colorectal cancer in European populations: a nested case-control study. BMJ 2010;340: b5500.

27 Devereux G, Turner SW, Craig LC, et al. Low maternal vitamin E intake during pregnancy is associated with asthma in 5-year-old children. Am J Respir Crit Care Med 2006;174:499-507.

28 Troisi RJ, Willett WC, Weiss ST, et al. A prospective study of diet and adult-onset asthma. Am J Respir Crit Care Med 1995;151:1401-8.

29 Anandan C, Nurmatov U, Sheikh A. Omega 3 and 6 oils for primary prevention of allergic disease: systematic review and meta-analysis. Allergy 2009;64: 840-8.

30 Klemens CM, Berman DR, Mozurkewich EL. The effect of perinatal omega-3 fatty acid supplementation on inflammatory markers and allergic diseases: a systematic review. BJOG 2011;118:916-25.

31 de Marco R, Cerveri I, Bugiani M, et al. An undetected burden of asthma in Italy: the relationship between clinical and epidemiological diagnosis of asthma. Eur Respir J 1998;11:599-605.

32 Toren K, Brisman J, Jarvholm B. Asthma and asthma-like symptoms in adults assessed by questionnaires. A literature review. Chest 1993;104:600-8. 